Studies in African Linguistics

Volume 22, Number 2, August 1991

\title{
A STUDY OF THE STYLISTIC MARKERS OF THE LANGUAGE OF CARTOONS IN NIGERIA
}

\author{
Modupe M. Alimi \\ University of Agriculture \\ Abeokuta, Nigeria
}

\begin{abstract}
This paper discusses the stylistic characteristics of the language of cartoons in some Nigerian newspapers. The analysis focuses on printing styles, stylistic registers, and textual features. The author concludes that the informal style (exemplified by the occurrence of Pidgin English, colloquial forms, loan blends, ellipsis, and telegraphic sentences) characterizes the language of the cartoons. Thus, cartoonists use language as an artistic medium in which various options of language are explored for effective communication.
\end{abstract}

\section{Introduction}

1.1. Language as a socio-cultural phenomenon. There are over four hundred languages spoken in Nigeria, making it difficult, if not impossible to choose a single indigenous language as the official language throughout the country. Over the years, therefore, English has been, and is the official language, the language of law, business, journalism, and religion in Nigeria. It is also the language of instruction in schools, and hence English is a second language for many Nigerians.

Language functions within a socio-cultural context. Saussure's frequently quoted words, "language is a social fact," attest to this. Thus, the sociologist focuses on explaining as well as predicting how symbolizations are directly related to social variables such as users and context. Anthropologists, on the other hand (Malinowski [1923] for instance), affirm that utterances are meaningful only when they are related to the context of their use. The dimensions of context therefore include the "cultural occupation" and "preoccupation" of the people speaking the language. In a situation like that in Nigeria, the issue of domestication becomes 
relevant if English language is to function effectively as a means of communication.

Since language exists or functions within a socio-cultural context, variation in language is an inevitable phenomenon. Halliday [1978] considers variation in language as the expression of some fundamental attributes of the social system. Thus, language users are compelled by different circumstances to use language differently.

1.2. Cartoons. Cartoons are simplified drawings, representational or symbolic, that make humorous points. They are widely used as a means of social satire in Nigeria to comment on political events, domestic or family matters, and undesirable behaviours such as cheating and immorality. In Nigeria today, many newspapers (perhaps all) publish cartoons daily. Therefore, cartooning has become an important aspect of journalism in the country. A major issue raised so far is the relationship between culture and language as well as the question of language varieties. It is against this background that the language of cartoons in Nigerian newspapers is examined. Sample cartoons are drawn from some Nigerian newspapers. 1 The discussion focuses on unique styles of printing, stylistic registers, and textual features.

\section{Analysis and Discussion}

2.1. Styles of printing. Various aspects of printing such as the relative sizes of different portions of letters, positions of dots, capitalisation, italics, and different punctuation devices were found to be stylistically significant in cartoons. The data revealed that the meaning-carrying units in sentences are often capitalised as a way of attracting and sustaining the reader's attention. The use of capitals is also significant because it establishes a contrast between the key items and the less important items in cartoons. The Daily Sketch cartoon of September 4, 1985 was a ridicule of the Nigerian Police (see Cartoon 1). The police officer was criticized for demanding "kola" (Yoruba's implicit word for a bribe) from drivers. On this occasion, however, no "KOLA" (capitalised) was offered because the days of offering "kola" had gone. Another illustration is found in a National Concord cartoon of July 23,1985 . This cartoon was an oblique swipe at the WAI ${ }^{2}$ (War Against Indiscipline) culture: Too much of WAI had an unintended effect of making the Eagles (a Nigerian football team) "QUEUE" (capitalized) for the ball

\footnotetext{
${ }^{1}$ Sample cartoons used in this study were culled from the Daily Sketch, Nigerian Tribune, The Vanguard, The Punch, National Concord, and The Guardian. The samples were collected between July, 1984 and March, 1986.

${ }^{2}$ War Against Indiscipline (WAI) was the name of a campaign launched against all forms of indiscipline, misconduct, and corruption by the Buhari regime.
} 


\section{Cartoon 1. 두 1985 Daily Sketch}

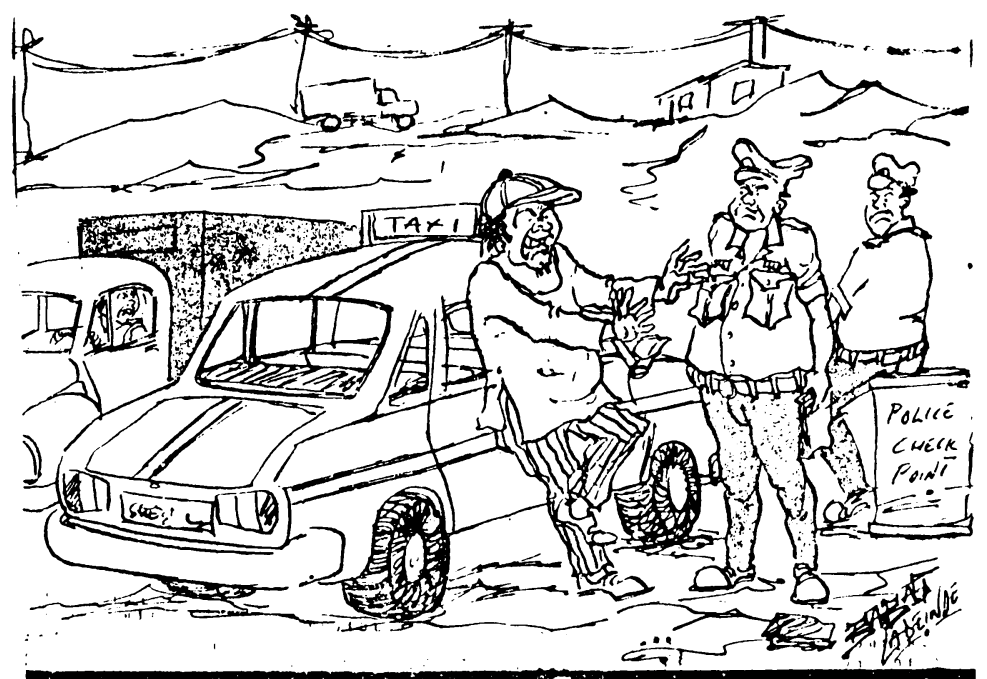

"Look. those days have gone. No more KOLA."

instead of playing it. Two other illustrations are found in The Vanguard cartoons of March 16 and August 6,1985. In the former, a parent rebukes his son for opting to be a doctor (a profession no longer lucrative because of the economic hardships in the country) and insists that his son must be a "SOLDIER". The latter comments on Nigerian soldiers "who never die but get PREGNANT after retirement" (depicting a rotund apparent former army officer in a gym). In these two examples, "soldier" and "pregnant" respectively are capitalised. In the Daily Sketch edition of January 22, 1986, Paddy's (the stock character in Daily Sketch fill cartoons) discussion over the telephone with Umaru Dikko, an ex-politician in exile in Britain, goes thus:

(1) "Hello! Is that UMARU? Got nothing to lose if you come home now. You may turn out to be a SAINT!"

As in the other examples, "UMARU" and "SAINT" are capitalised to refer implicitly to the lack of fair play that characterised the trial and retrial of some expoliticians in the country.

Where all items in a cartoon are capitalised, it was observed that the size of the lettering is often varied for contrast. In the National Concord of July 4, 1985, the widening gap between the rich and the poor is portrayed not only in terms of the 
size of the caricatures of rich man and the poor man but in terms of the size of the letters of "RICHMAN" and "POORMAN".

Print contrast (bold and light prints) was also found to be used significantly in cartoons to highlight or play down, as the case may be, words of varying degrees of importance. The Punch cartoon of September 5, 1985 featured a desperate minister who visits a "LONDON TRAINED HERBALIST", "CHIEF JAGBAJANTIS" in a bid to be retained in the Babangida cabinet. While the name of the herbalist was written in a darker shade, the name of the institution where he was trained was printed in a lighter shade.

Another relevant observation is the symbolic use of print markers. Letterings were used symbolically to communicate a desired meaning. The cracks in the lettering of " 8 " (Organisation of African Unity) in the Nigerian Tribune of September 4, 1984 is symbolic of the crisis and the disintegration in the organisation.

The "snaky" lettering of " $\boldsymbol{N} \mathbf{5} \boldsymbol{D}$ " (Nigeria Security Organisation) in the Daily Sketch of September 10, 1985 could be symbolic of deceit and brutality in the organization. Obviously, therefore, print markers are used in cartoons as a way of foregrounding items considered important to an understanding of issues and persons in the society.

2.2. Stylistic registers. The analysis in this section reveals three types of sentences in the language of cartoons: Pidgin English sentences, colloquial sentences, and standard English sentences.

2.2.1. Pidgin English. Although the origin of Pidgin English is associated with the need for a medium of communication between the people along the West African coast and the Portuguese traders, Pidgin English has almost assumed the status of a lingua franca in some parts of Nigeria. In cartoons, Pidgin is found to be the language of identification. Members of the Police Force (usually at police check points), the Customs, and the Army are addressed (or they address members of the public) in Pidgin. A few examples are cited below:

(2) A motorist to a policeman at a check point (National Concord, November 12 , 1985-see Cartoon 2):

Oga O.C., no be > 5 I dey give you, why > 10 now?

'But Officer, I used to give $>5$, why are you now asking for $>10$ ?' 


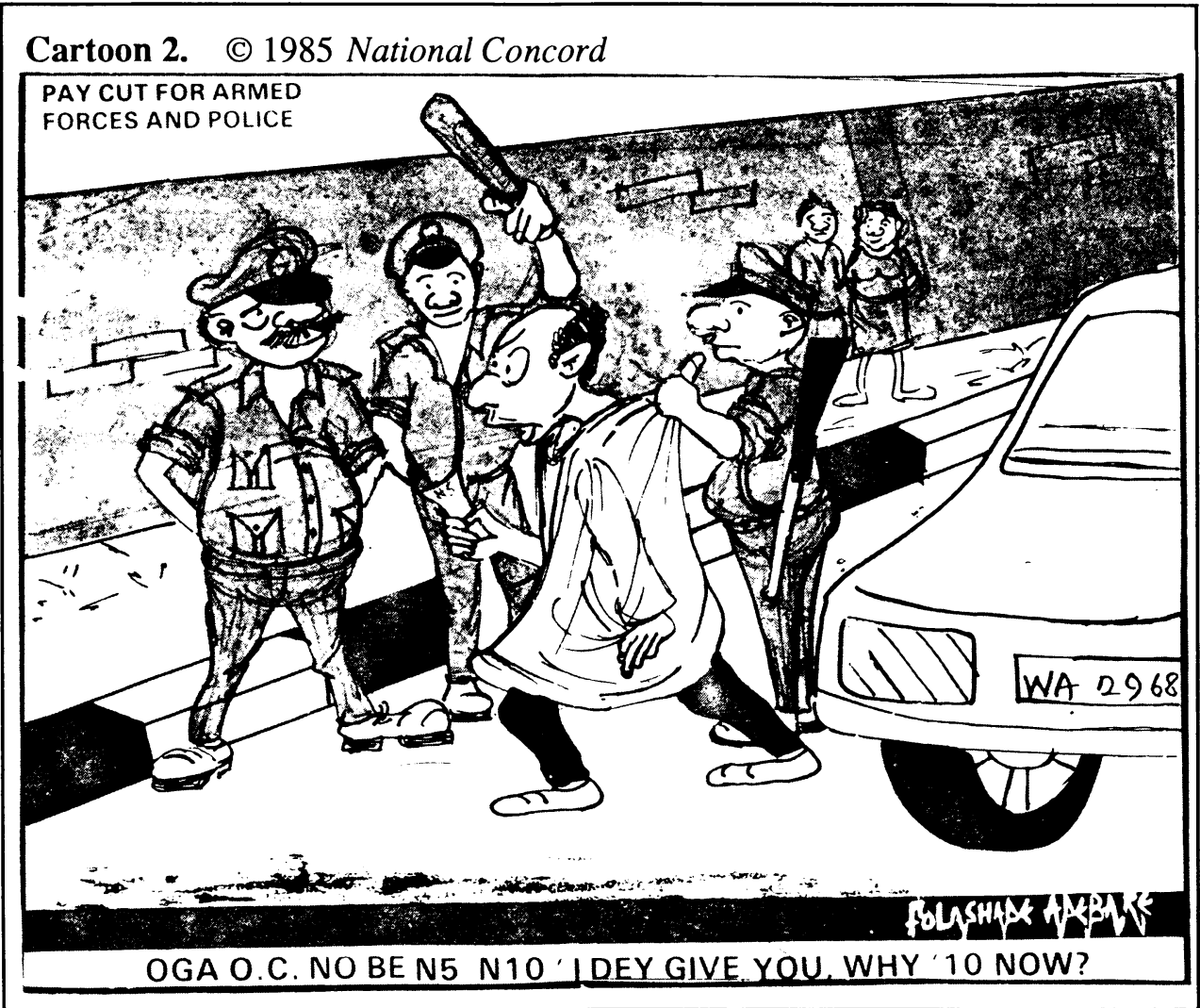

(3) Driver of crashed bus to a policeman (The Punch, November 4, 1985-see Cartoon 3):

No, O.C., ... I no drink tombo ... na the railing jump in front of my Molue.

'No Officer, I haven't been drinking Tombo (a type of native gin) ... it's the railing that jumped in front of my bus.'

(4) A female motorist to a policeman fondling her at a check point (The Punch, September 9, 1985):

I beg O.C., which kind search be this?

'Officer, what type of search are you carrying out?' 


\section{Cartoon 3. ㄷ 1985 The Punch}

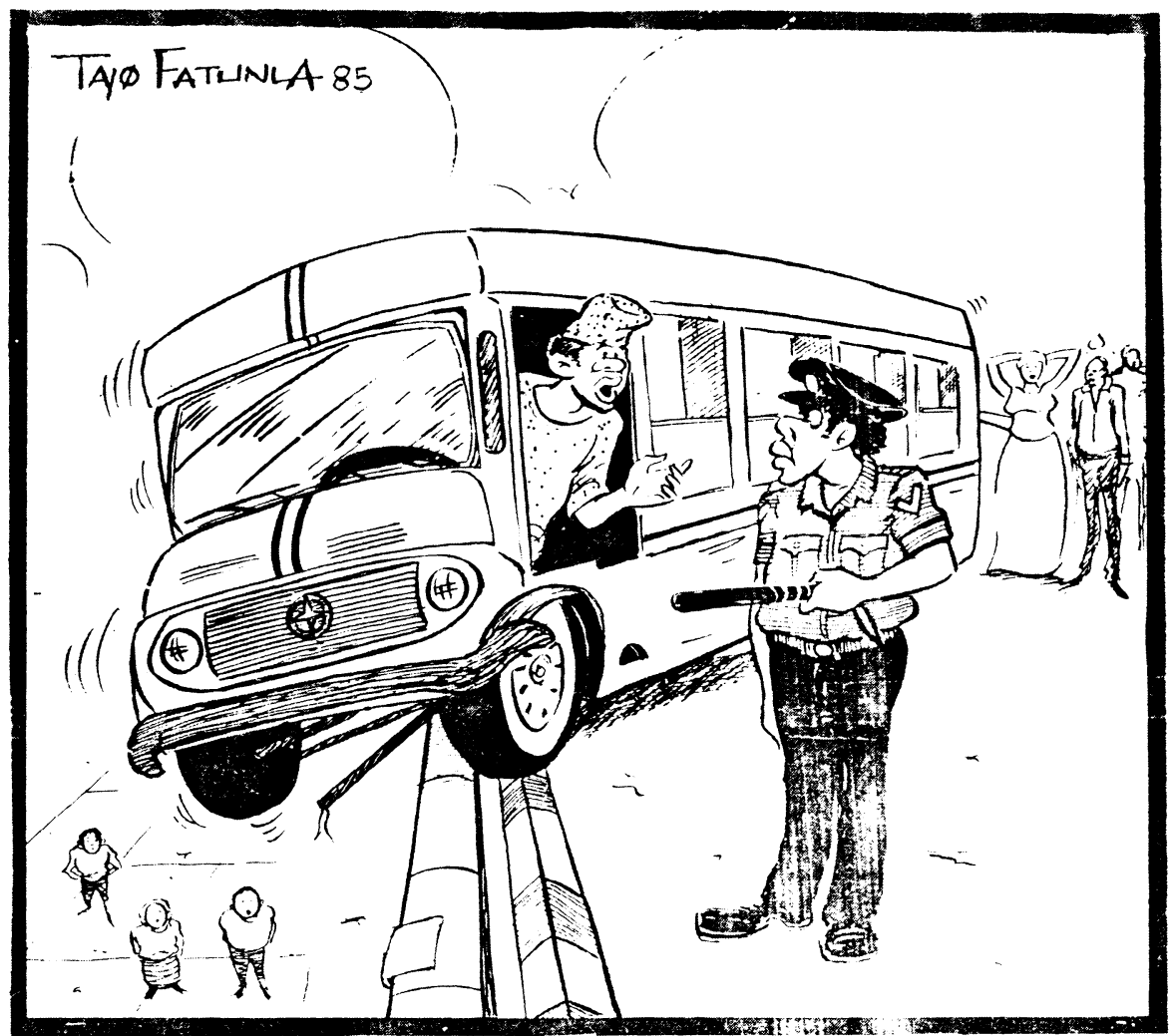

"Vo ... O.C. I no drink tombo ... na the railing jump in tront at my Molue"

(5) A headmaster sitting alone at a school registration table outside a school (The Punch, April 4, 1985):

Just one registration since morning?... E be like say education don get $K$ leg? 'Just one pupil has turned up for registration since morning? It appears education is no longer important.' 
(6) Husband to wife at dinner table, as child clamours for more food (National Concord, November 5, 1985):

Mama bomboy, warn yar pikin, if I hear am ask for rice again ...!

'Madam, warn your son to stop asking for rice ...!'

(7) One motorist to another in a line of cars approaching a check point in anticipation of the usual demands by police (National Concord, March 28, 1985):

Ol' boy, na check point o-you get 5 change me?

'My friend, it's a check point ahead - could you please change my , 5 bill into small denominations?'

(8) A man to a police officer lying over the front of a car at a check point (The Punch, August 14, 1985):

Haba O.C. Na because of pocket money you dey do this kind stunt? Abi you wan die like cockroach?

'What, officer. Just because you want to collect a paltry sum you do this kind of a stunt? Why do you want to die like a cockroach?'

(9) One armed bandit to his compatriot firing from a car as they speed away from the police (The Punch, July 30, 1985):

Make you no waste the bullets... Dem no fit catch us with that their yeye Land-Rover wey old pass my granny and that dem yeye gun wey resemble toy!

'Don't waste your bullets ... They cannot catch up with us with their ragged Landrover which is older than my grandmother and their toy-like, worthless gun!'

As part of the efforts to domesticate English in Nigeria, it appears Pidgin English has emerged as the language of the common man, the down-trodden, and the underdog. Thus, in cartoons, conversation among this group is in the common code as illustrated by the following:

(10) One man speaking about another whom he has just knocked down, as we see money on the ground and electrical wires above (The Punch, 1985):

I go teach am sense well well! He wan sell LAND to me under NEPA WIRE.

'I'm going to teach him a good lesson for playing on my intelligence! He wanted to sell me a piece of land under high tension wires.' 
(11) One newspaper salesman to another about a paper carrying the news headline "Why we toppled Obote-New Ugandan leaders" (The Punch, August 1, 1985):

I no know book but I know say whether di toppled leader good or e no good, somebody is power crazy.

'I don't know whether the toppled leader is good or bad, I would rather say someone is power drunk.'

Pidgin English also provides the medium through which the "ordinary man" expresses his views and disappointments over problems in the society, as in the following examples:

(12) A nearly naked man is hearing the name "Dikko" (Alhaji Umaru Dikko-see example (1)) all around him (The Punch, June 11, 1985):

Bo ... this billion naira name don dey tire me o! ... Abi we go begin chop am? 'I'm tired of the noise over the name Umaru Dikko. How can this be a substitute for food?'

(13) A boss and his driver converse as they drive (The Guardian, December 17, 1985):

Boss: ... But I see nothing wrong with your sacrificing a mere $1 \%$ of your salary towards the nation's economic recovery.

Driver: Oga, the thing be say my sacrifice pass your own.

'Sir, I think I will be sacrificing more than you.'

Boss: How? I'm giving a whole $20 \%$ of mine ...

Driver: Em ... Oga na only one wife and two children you get plus your fringe benefits.

'Sir, you have only one wife and two children. In addition you are entitled to fringe benefits.'

Boss: What about that?

Driver: For me, na my wife, six children and my dead uncle's family with no fringe benefits.

'You see, I have my wife, six children, and my dead uncle's family to look after, and I'm not entitled to any fringe benefits.

The implication of the conversation in (13) is that the Economic Emergency Recovery Fund (deducted from workers' salaries by the government) is meaningless because of its adverse effect on the low income earners, who are worse hit since they do not enjoy the privileges which the high class enjoys. 
Although the orthography and vocabulary of some of the Pidgin English forms identified in cartoons may not be Pidgin proper (effective surveillance no dey, fringe benefits, education no sufficient), it appears that English has been thoroughly "groomed" to meet the need for pungent ridicule and character leveling in cartoons.

2.2.2. Colloquial forms. The use of colloquial forms is another dimension of domestication in the language of cartoons. Colloquial language is that language which is acceptable in everyday talk but is unacceptable in the standard written form. One characteristic shared by the colloquial forms observed in cartoons is the presence of vernacular forms. A few examples of vernacular forms are reproduced below with the items in question shown in bold and the source of the forms identified:

(14) A landlord speaking to his tenant as he collects rent (Daily Sketch, September 29, 1985):

Next month you must pay jara or I flush you out.

(jara from Hausa gyara referring to extra or additional money or goods)

(15) A man talking to his wife in their poorly furnished room, as he reads a newspaper with the headline "Bread costs more" (Daily Sketch, February 2, 1986 - see Cartoon 4):

Is BREAD Oyinbo food or our own?

(Oyinbo $=$ Yoruba word for 'white man')

(16) Man speaking to his wife outside their small house on a wharf (Daily Sketch, January 4, 1985):

Rara $O$, Don't tell me there is no meat in the pot.

(rara = Yoruba word for 'no') 


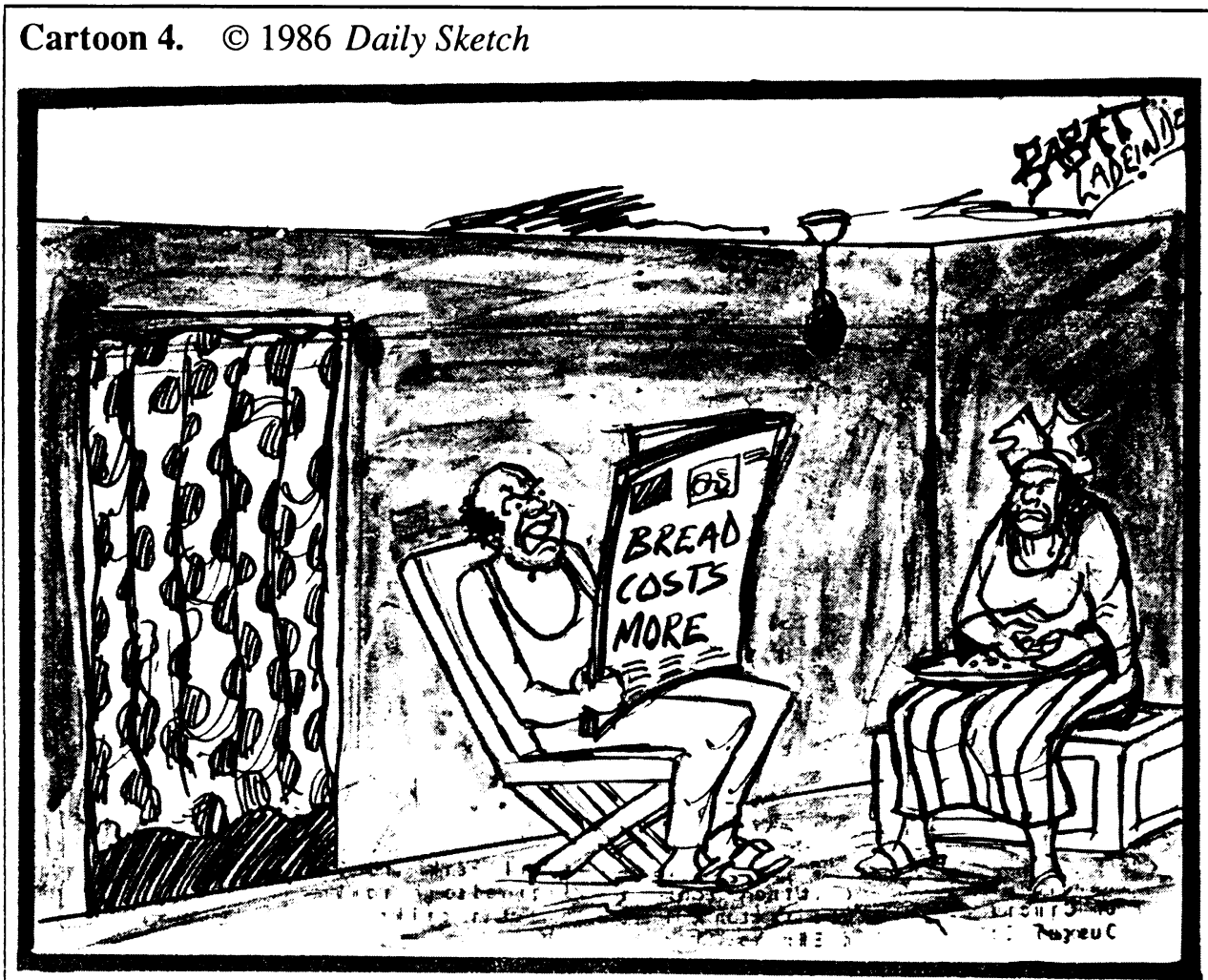

Is BREAD Oyinbo food or our own?

(17) A perplexed man, under the headline "5,000 may be sacked at NTA stations", after reciting a litany of claimed new government policies against corruption (The Nigeria Tribune, January 23, 1985):

Chineke, where art thou?

(Chineke = Igbo word for 'God')

(18) Conversation between a woman working in the kitchen and her husband (the Punch, July 16, 1985):

Wife: Dear, I want a house boy to give me a helping hand.

Husband: House boy! Eh, why not a house girl? 
Wife: Hm-m, why do you prefer a house girl?

Husband: You nko?

(nko from Yoruba 'how about...?', i.e. 'Why do YOU prefer a house BOY?')

One of the results of the use of colloquial forms is code mixing. Thus, certain lexical items such as those boldfaced above are used in standard English sentences. In addition to denoting informality, the use of colloquial forms is also one of the features of Nigerian English observed in cartoons.

2.2.3. Standard English sentences. Standard English sentences are sentences devoid of code mixing and other forms of linguistic interference. Such sentences conform to the grammatical norms of world Standard English. In using Standard English sentences, it appears that cartoonists deliberately go for the simple and compound structures as shown in the following examples:

(19) A gallivanting politician carries a suitcase marked with the names of foreign capitals as his conscience tugs to hold him back (National Concord, September 17, 1985):

Ah! I'm not following you down to Nigeria o!

(This sentence is regarded as Standard English in spite of the non-standard use of "following" in place of "accompanying". This usage is considered stylistic or dialectal in this case.)

(20) A sportscaster as the Nigerian team kicks a goal past the Russian goalkeeper (Vanguard, September 11, 1985):

And so, Ladies and Gentlemen, the RUSSIANS have RUSHED themselves out of the game.

(21) A father in his patched up house addresses his wife and six children (National Concord, November 25, 1985-see Cartoon 5):

My pay has been cut. You are all being re-deployed to the village. You stay with my parents there.

Cartoonists' preference therefore for the simple and compound structures might be connected with the need for creation and maintenance of an air of simplicity. 


\section{Cartoon 5. (C) 1985 National Concord}

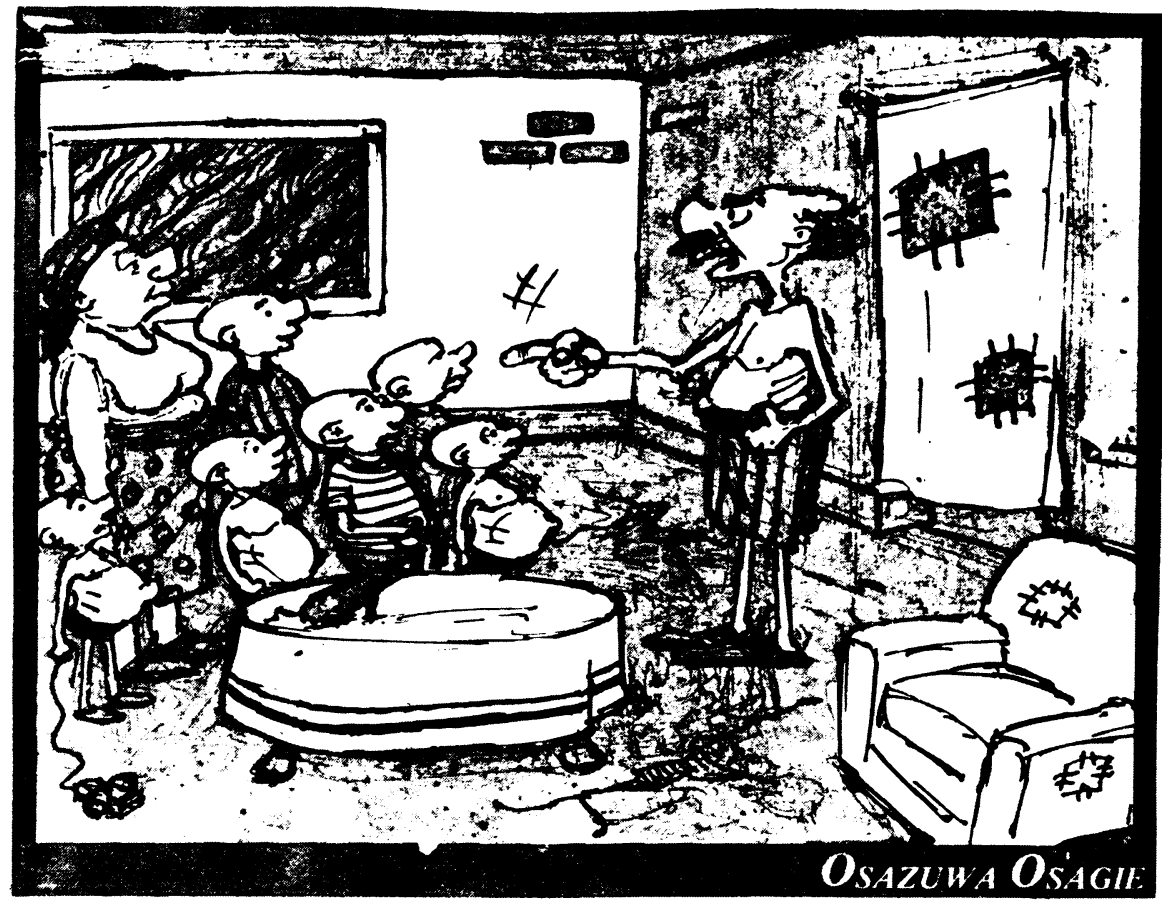

INIY PAY HAS BEEN CUT. YOU ARE ALL BEING RE-DEPLOYED TO THE VILLAGE. YOU STAY WITH MY PARENTS THERE.

Another interesting feature of the Standard English sentences in cartoons is their elliptical nature. Consider the conversation in (22) from The Guardian, December 2, 1985. The parentheses indicate ellipted items:

A: What are these, Sam?

B: (They are) 50 Christmas cards I want to send to some very important people!

A: (That's) Incredible!... You are jobless and you want to send cards to 50 people? ... Where did you get the money?

B: I borrowed it!

A: That doesn't sound sensible to me! Anyway, who are the people you call important?

B: (They are) The directors of the 20 companies I applied to! 
The omission of the items in parentheses above might have been deliberate to maintain simplicity and informality. Furthermore, cartoons need to present the written message as if it were a message in the spoken medium, and the use of ellipsis has further enhanced the spoken medium.

\subsection{Textual characteristics}

2.3.1. Humour in cartoons. Humour is of paramount importance to cartoons, and both the verbal and non-verbal cues in cartoons are fertile grounds for humour. In creating humour, the Nigerian cartoonist explores possible combinations of lexical items. This results in a mismatch between the context of the speech act and the subject matter. The oddity of the situation creates fun for the readers. In the interchange in (23), the increase in the number of accidents is attributed to the "carelessness" and "impatience" of the roads, not of the road users:

(23) Discussion between two men observing a sign "Road Safety Week" (The Guardian, March 22, 1985):

A: Hmm ... Road Safety Week! Campaign to make our roads safe, abi?

B: No! ... Campaign to make motorists sit up! The blighters are too careless and impatient!

A: I no gree! ... Our roads are too careless and impatient!

Another source of humour in Nigerian cartoons is the use of deliberate distortions of speech. This involves misinterpretations of abbreviated forms (names and titles) and expressions (including codes and the National Pledge) to create a new meaning. ECOWAS (Economic Community of West African States) was reinterpreted as "Economic Cowards of West African Sufferheads" (The Punch, 1985) to reflect the organisation's incompetence and lack of seriousness in handling matters affecting member states. The Ibadan Refuse Disposal Board was renamed "Ibadan Refuse Dispersal Board" (Daily Sketch, July 10, 1985-see Cartoon 6).

The Guardian cartoon of September 3, 1985 had a modified version of the Nigerian National Pledge which worker recites to his boss:

(24) I pledge to Nigeria our country, To be faithful, loyal and honest, ... When the fugitives are extradited 


\section{Cartoon 6. C 1985 Daily Sketch}

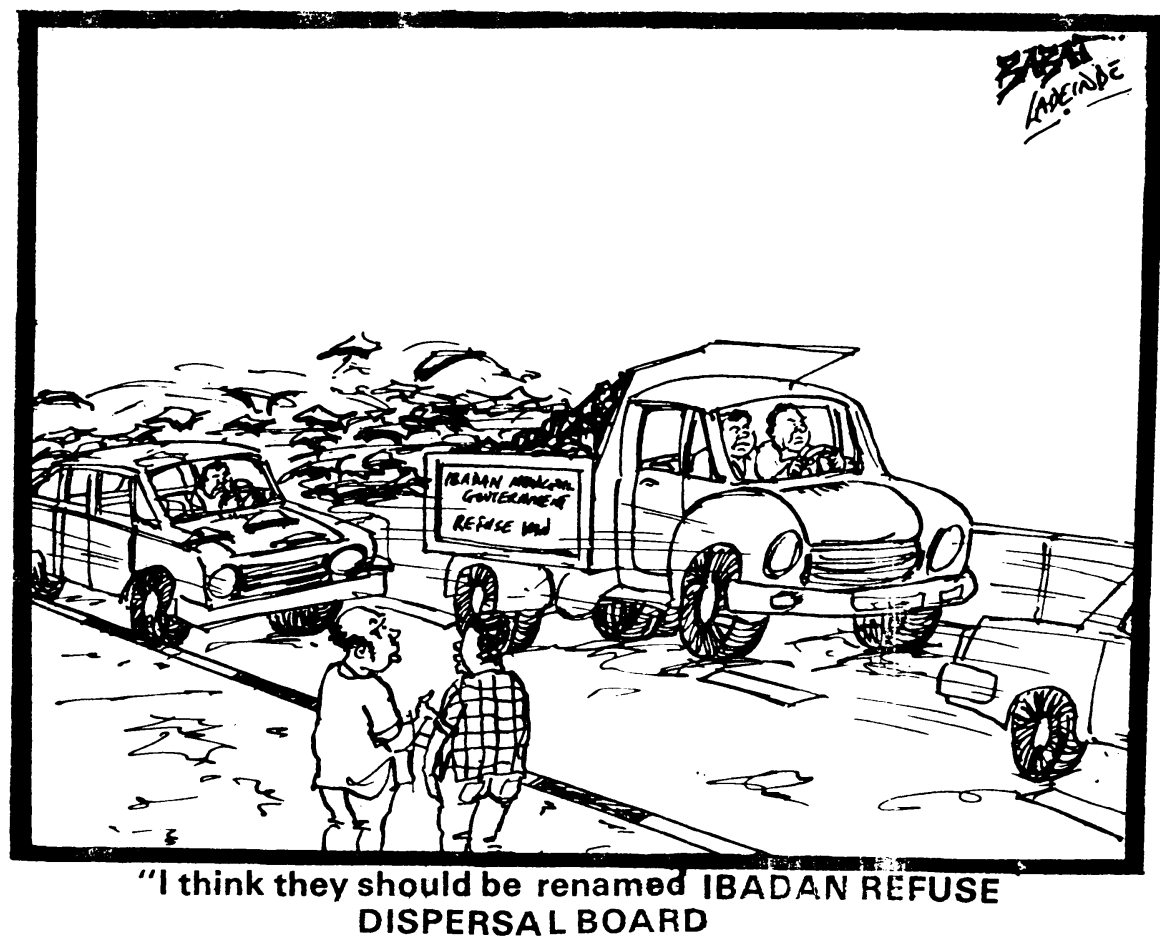

To serve Nigeria with all my strength

When I'm not hungry,

To defend her unity, ...

When I become a soldier,

And uphold her honour and glory, ...

Like what I did when we won the U-16 World Cup,

So help me God!

The modified version of the National Pledge above was not meant to create just fun, it has a wider application, because when the man who recites the pledge is asked to disclose the source of his version, his reply is, "From my home under the bridge sir!" The implication is that patriotism and nationalism can only be 
achieved when certain conditions are met, and it is these conditions (boldfaced in (24)) that have been added to the National Pledge.

Adaptation of serious subjects and styles constitutes another source of humour in cartoons. The National Concord of February 15, 1985 published a parody of the Ten Commandments entitled "Commandment of the helpless":

(25) Thou shall have no job,

Thou shall not solicit,

Thou shall not give,

Thou shall not take,

Thou shall not complain,

Thou shall see no evil,

Thou shall talk no evil,

Thou shall be heavily taxed,

Thou must be disciplined,

Thou shall earn little,

Thou shall know thy pledge,

Thou shall queue for rice,

Thou shall live by tax clearance,

Thou shall not check out,

Thou shall be patriotic.

The "Commandment of the helpless" is a criticism of some of the policies of the Buhari/Idiagbon regime. It is in fact an exploration of some fundamental problems in the country. The cartoonist does not only elicit the laughter reflex, but he also uses various linguistic devices as a vehicle for the exploration of some of the evils plaguing the nation.

2.2.2. The informal style. Informality in the language of cartoons is reflected in the use of a variety of forms such as Pidgin English and colloquial forms discussed earlier. Apart from its role as the language of identification, Pidgin English is essentially one of the characteristics of the informal style in cartoons. It is one of the features that distinguishes cartoons from the formal components (news, editorials, features) of the newspapers. Informality in cartoons is also exemplified by the use of loan blends. In some cases, lexical items from Nigerian languages are interlarded with English expression to produce new words. In some other situations, two or more English lexical items are mingled harmoniously into compound words for the communication of a desired meaning. In one cartoon from the National Concord (November 20, 1984), a doctor gives the following diagnosis to one of his patients: 
(26) My friend, you are sufferin' from hungerneurosis, taxophobia, levymylitis, retrenchomania, etc. There is no known cure on earth ... My consultation fee is > 100 only!

This is an indirect reference to the prevailing harsh conditions in the country where citizens are perpetually confronted with different kinds of levies and other social ills such as retrenchment and hunger.

In another cartoon from the National Concord of June 23, 1985, some of the "Nigerian National Diseases" (NND) were identified as "long-legism" (favouratism) and "V.I.P.-ism" (love for superfluous titles). In a National Concord cartoon of March 12,1986, a politician speaking to a military officer blends politics and tricks, saying,

(27) In four years time, our colleagues studying politricks abroad would have finished their courses...

As Nigerians looked forward to 1990 elections, a cartoon in The Vanguard of February 28, 1986 referred to one of the emerging political parties as the "Nigerian Dabaruing Party". Dabaru is a Yoruba word meaning 'to confuse, to set in disarray, to spoil'. This word is blended with the English -ing ending to produce the name of a party. The implication of this name is that it is a party that will stir confusion in the nation. Another cartoon in the National Concord of March 10, 1986 described Nigeria as "Naija Wahala". "Naija" is an abbreviated vernacular form of Nigeria, and this is combined with the Hausa/Yoruba word for problem, wahala, to imply that Nigeria is a problematic nation. In a cartoon from the National Concord of February 22, 1985, WAI (War Against Indiscipline) is combined with -tamin from vitamin to form "WAI-tamin", a pill which was recommended to General Buhari to combat the forces of the Nigeria Medical Association (NMA) - see Cartoon 7. In another cartoon of the National Concord (March 12, 1985), General Buhari pleads with Doctor I.M.F. (International Monetary Fund) for his bed-ridden patient, "Naija Economy", saying,

(28) Hope you aren't going to administer hungering on him like others!

This implicitly refers to one of the adverse effects of the I.M.F. loan-hunger. The word "Adisco" (an informal nickname for Adisa) has become a household name in cartoons. Although the language of expression in the Nigerian media is English, the variety of English observed in cartoons permits words or expressions which are not English, but are relevant to an understanding of the social, political, economic, and cultural problems in the country. 


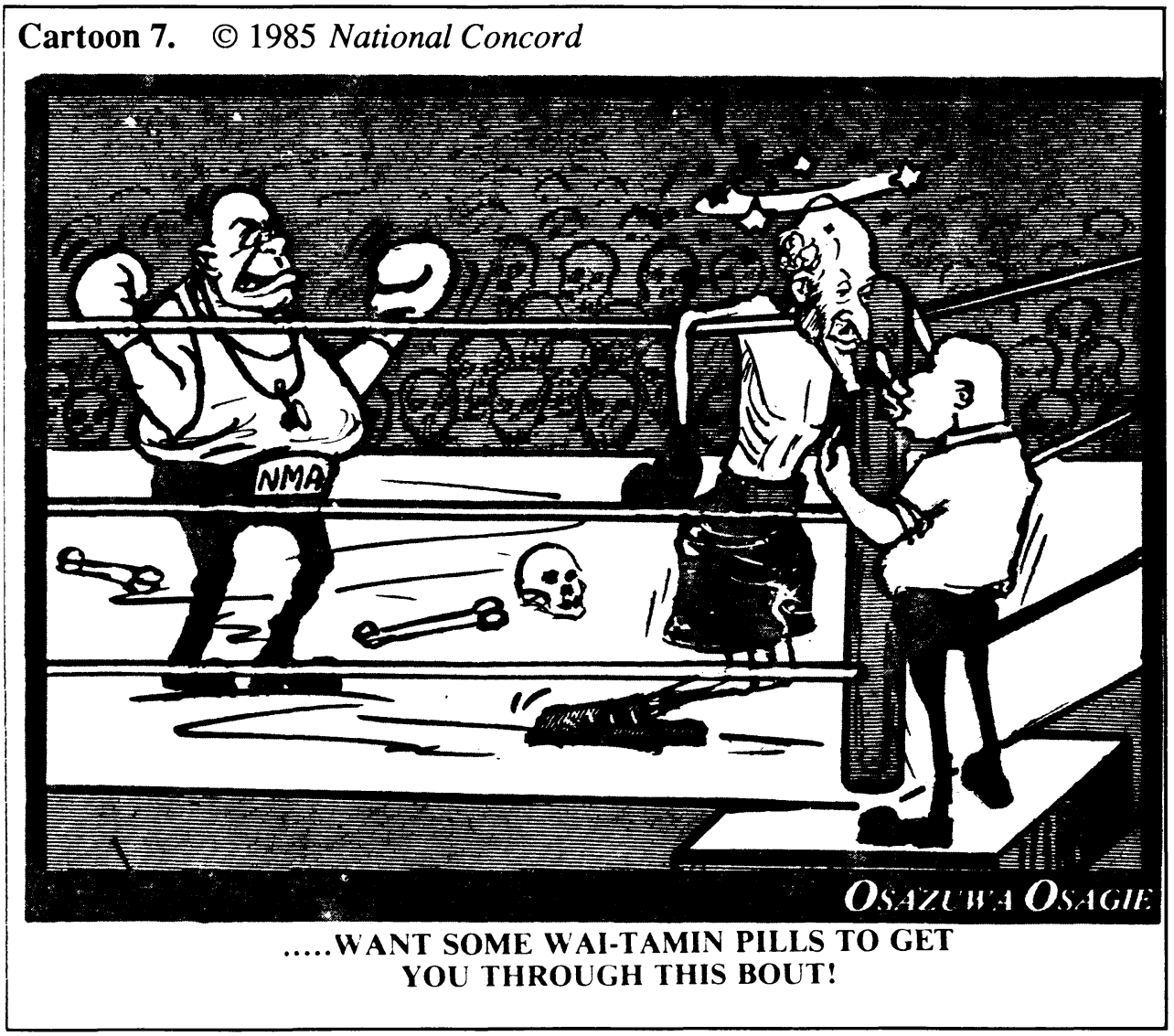

From the foregoing discussion, it is obvious that the language of cartoons is not as direct as the language of news reporting. It is also obvious that the language of cartoons is informal. In fact the style exhibited in cartoons may be described as an amalgam of forms.

\section{Conclusion}

At the beginning of this paper, the term "domestication" was used in relation to the utility of English in a multilingual society like Nigeria. Our aim in this paper has been to highlight the significant stylistic characteristics of the language of cartoons. It is important to note that the needs of the users of English, including cartoonists, in Nigeria are varied. Nigerian cartoonists have therefore succeeded in using the cartoon, an art form, as a medium of fostering a new language, a new kind of English. Thus, we may conclude that in terms of styles of printing, stylistic 
registers, and textual characteristics, English language has been (and still is) suitably adapted or "tamed" to meet the needs of cartoonists to comment on, or reflect the social, cultural, economic, and political events in the country.

\section{REFERENCES}

Alimi, Modupe M. 1986. “Communicating through cartoons: a psycholinguistic study of the language of cartoons in some Nigerian newspapers." Unpublished $\mathrm{PhD}$ dissertation, Department of Language Arts, University of Ibadan, Nigeria.

Halliday, M.A.K. 1978. Language as Social Semiotic: the Social Interpretation of Language and Meaning. London: Edward Arnold.

Malinowski, Bronislaw. 1923. "The problem of meaning in primitive languages." Supplement 1 to C.K. Ogden and I.A. Richards, The Meaning of Meaning, pp. 296-346. International Library of Psychology, Philosophy, and Scientific Method. London: Kegan Paul. 